\title{
Sensitivity analysis of changes in human physiological indicators observed in soundscapes
}

\author{
Zhongzhe $\mathrm{Li}^{\mathrm{a}}$, Jian Kang ${ }^{\mathrm{a}, \mathrm{b}^{*}}$
}

${ }^{a}$ Key Laboratory of Cold Region Urban and Rural Human Settlement Environment Science and Technology, Ministry of Industry and Information Technology, School of Architecture, Harbin Institute of Technology, Harbin, China.

${ }^{\mathrm{b}} \mathrm{UCL}$ Institute for Environmental Design and Engineering, University College London (UCL), London, United Kingdom.

*Corresponding Author: J.kang@ucl.ac.uk, UCL Institute for Environmental Design and Engineering, The Bartlett, University College London (UCL), London WC1H 0NN, United Kingdom. Tel: +44 (0)20 31087338.

Received 19 March 2019, Revised 30 May 2019, Accepted 3 June 2019, Available online 12 June 2019.

\begin{abstract}
The objective of this study was to determine changes in physiological indicators with time in different soundscapes and their correlation with the results of subjective restorative evaluation. Physiological indicators including the heart rate (HR), amplitude of the R-wave $(\Delta \mathrm{R})$, heart rate variability (HRV), electroencephalography alpha reactivity ( $\alpha$-EEG), electroencephalography beta reactivity $(\beta-E E G)$, eye blink frequency $(B F)$, respiratory frequency $(\mathrm{RF})$, respiratory depth $(\mathrm{RD})$, skin conductance level (SCL), and skin temperature (ST) were measured and analysed through audio-visual reduction in a laboratory, and the obtained data were compared with the answers to a perceived restorativeness soundscape scale survey. Through the analysis of variance by a repeated measures method, it was found that all physiological indicators (except for $\alpha$-EEG) changed after one minute of measurements. Furthermore, BF and ST were not affected by the changes in the soundscape type, and the natural sound decreased the levels of HR, $\mathrm{RF}$, and RD and increased the values of $\Delta \mathrm{R}, \mathrm{HRV}, \alpha-\mathrm{EEG}$, and $\beta$-EEG. In addition, a
\end{abstract}


canonical correlation analysis was performed to determine the correlation between the physiological indicators and subjective evaluation factors. The relationship between the physiological parameters measured within the first minute and results of subjective evaluation was relatively strong but insufficient for accurately interpreting the obtained physiological responses using only the subjective evaluation data.

Keywords: soundscape; physiological response; time effect; subjective evaluation

\section{Introduction}

Perception and understanding of acoustic environments by humans have been the focus of many studies on soundscapes (Kang, Aletta, Gjestland, Brown, Botteldooren, Schulte-Fortkamp, Lercher, Van Kamp, Genuit, Fiebig, \& Coelho, 2016). Since Kaplan (Kaplan \& Kaplan, 1989) and Ulrich (Ulrich, Simons, Losito, Fiorito, Miles, \& Zelson, 1991) formulated the attention restoration theory (ART) and stress restoration theory (SRT), the investigation of the restoration effect produced by soundscapes has never stopped. A series of previous studies revealed that soundscapes strongly affected the human health and quality of life (Von Kamp, Klaeboe, Kruize, Brown, \& Lercher, 2016; Von Lindern, Hartig, \& Lercher, 2016; Shepherd, Welch, Dirks, \& McBride, 2013); in particular, tranquil soundscapes helped people recover from stress. It was also found that the natural environment had a positive effect on restoration processes (Hartig \& Staats, 2003; Hartig, Evans, Jamner, Davis, \& Gärling, 2003; Ratcliffe, Gatersleben, \& Sowden, 2013). At the same time, a large number of restorative soundscape evaluation indicators were established, and the majority of related studies were based on a survey questionnaire data gathering method. Hartig, Korpela, Evans, \& Gärling (1996), developed a perceived environmental restorativeness scale (PRS), which described the results of a recovery environment using four characteristics (Fascination, Being-Away, Compatibility, and Extent). Afterwards, researchers used various statistical methods to study and improve the PRS variables (Herzog, Colleen, Maguire, \& Nebel, 2003; Laumann, Gärling, \& Stormark, 2001; Rayne, 2013).

However, the soundscape restoration effect should correlate not only with subjective evaluation data (which a convenient term denoting 'judgmental data' in this study), but also with physiological parameters. Moreover, the emotions caused by sound stimulation can be also reflected by physiological indicators. Therefore, multiple studies on the physiological and emotional responses to sound stimulation have been conducted. Bradley and Lang are the pioneers of the emotional sound 
field and builders of the emotional sound database (IADS), but the sound samples they used in the experiment were only six-second long (Bradley \& Lang, 2000). Other studies focused mostly on noise and transient sound stimuli, which also lasted only six seconds (Shepherd, Hautus, Lee, \& Mulgrew, 2016). The study of Hume and Ahtamad on emotions involved experiments with durations of only eight seconds (Hume \& Ahtamad, 2013). Musical studies focused on the physiological responses caused by emotions at very small durations of the sound stimuli. For example, the sequence of music used in the study of Chuen, Sears, \& McAdams (2016) lasted 15 s, while that utilised in the work of Sammler, Grigutsch, Fritz, \& Koelsch (2010) lasted one minute.

The cognitive process of hearing is very short, and the corresponding emotion can be instantly aroused by sound stimulation. However, several seconds may not be sufficient to examine the physiological changes caused by soundscapes because, except for some indicators directly controlled by the sympathetic nervous system, most physiological changes are not instantaneous and relatively slow. Therefore, duration is a very important factor when studying the physiological effects of soundscapes. As of today, few studies on the physiological effects of a restorative sound environment on the human body have been conducted, and most of them were aimed at the verification of the environmental recovery theory. Because emotions are no longer the subject of the study, the stimuli utilised in the experiment become longer; as a result, the current works on soundscapes typically use the stimuli with durations of about $4 \mathrm{~min}$. For example, the data reported by Alvarsson, Wiens, \& Nilsson (2010) showed that after increasing the level of psychological stress, the sympathetic nervous system recovered faster in natural sounds than in unpleasant noise, and that at higher sound pressure levels (SPLs), it recovered more slowly. Medvedev, Shepherd, \& Hautus et al. (2015) proved that pleasant sound could accelerate the recovery of stress by conducting six recordings. The obtained results showed that the change in the heart rate (HR) was less apparent than the variations of skin resistance (Medvedev et al., 2015). Annerstedt, Jönsson, Wallergård, Johansson, Karlson, Grahn, Hansen, \& Währborg (2013) presented two different scene types (social stress test and natural environment) by using a virtual reality technology, measuring the cortisol level, and recording electrocardiograms (ECGs); the obtained results confirmed that people could relieve stress in a natural sound environment.

In the selection of physiological parameters, researchers generally choose sensitive indicators such as electrocardiograms (ECGs) and skin resistance. In some studies, the effects of sound on electroencephalograms (EEGs) (Schmidt \& Trainor, 
2001), computed tomography (CT) scans (Blood \& Zatorre, 2001), and functional magnetic resonance imaging results (Irwin, Hall, Peters, \& Plack, 2011) were also investigated. Ando \& Chen (1996) have conducted a series of studies on the relationship between $\alpha$-waves and subjective preference. It has been concluded that $\alpha$-waves require the intervals with durations of around $2.5 \mathrm{~s}$ to be awakened in a comfortable sound (Sato, Nishio, \& Ando, 2003). However, physiology represents an inclusive concept. Changes of a single indicator may be caused by transient emotions, and few people performed tests involving comprehensive physiological indicators. The correlation between the physical characteristics of soundscapes and subjective perception has been examined for many years (Kang et al., 2016), but most perceptual data are obtained using subjective questionnaires. The existing studies on the effects of soundscapes on physiology often focus on emotions; however, the relationship between the physiological response and subjective perception has not been investigated in detail.

What are the factors that affect the physiological responses of humans in a sound environment? As shown in Fig. 1, the aim of this study is to analyse various physiological indicators in a sound environment from three aspects: time, soundscape type, and subjective restoration evaluation. First, the action time of physiological indicators must be considered, and possible changes with time are to be monitored. Second, the effect of the soundscape type on physiological indicators must be determined without considering emotions. Finally, the existence of a relationship between the physiological indicators and results of subjective restoration evaluation should be discussed. By studying a number of physiological indicators, the following questions are addressed in this work. (1) Will the physiological indicators vary with the time of immersion in a soundscape, and what is the most reasonable time to detect their changes? (2) Do different soundscape types affect the physiological indicators, and do the observed effects exhibit a consistent trend? (3) Is there a correlation between the physiological indicators and subjective restorative evaluation data? Therefore, the effects of time and the soundscape type on physiological indicators were accessed by performing repeated measures variance analysis. In addition, a canonical correlation analysis method was used to determine the correlation between the physiological indicators and subjective evaluation factors. 


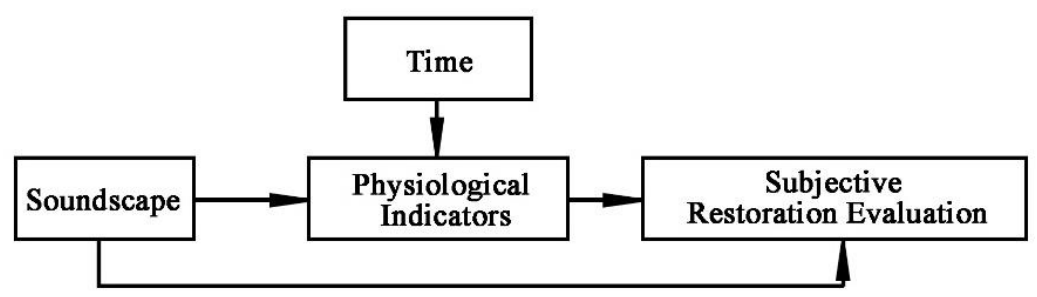

Figure 1. A theoretical framework describing the relationships between physiological indicators and other factors.

\section{Method}

In this study, a combination of physiological measurements and subjective evaluation was utilised. Four typical soundscape types were randomly presented to experimental participants whose physiological indicators were monitored by attached detectors. After that, the participants were asked to fill in a subjective questionnaire. The obtained data were analysed by statistical methods.

\subsection{Participants}

The participants were 66 unpaid undergraduate and graduate students with an average age of $21.82(\mathrm{SD}=3.438$; Min $=18 ; \operatorname{Max}=31)$, including 32 males and 34 females. All subjects did not have hearing problems or take any psychotropic drugs. They wore comfortable clothing and did not perform strenuous exercises within the two hours before the experiment or felt any fatigue.

\subsection{Stimuli}

One typical soundscape was selected from each of the four common soundscape categories (biological, geophysical, human, and traffic) (Axelsson, Nilsson, \& Berglund, 2010; Liu, Kang, Behm, \& Luo, 2013, 2014), including birdsong (a forest with birds at dawn), ocean (unattended waves and beaches on a calm sunny day), street (an outdoor shopping street full of hurrying pedestrians and hawking), and traffic (an intersection at the peak hour in the afternoon on a sunny day) ones. The soundscapes were captured by video (Gopro) and audio (SQuadriga II with BHS I) recording techniques. The equipment was placed $1.5 \mathrm{~m}$ above the ground. Five minutes of representative footage from each recording was used as the stimulation material for the experiment. Because of the difference in the recording environment, the background SPLs of the stimuli were different; therefore, they were normalised by an Adobe Audition digital audio workstation and calibrated using an HEAD Acoustics HMS IV system. Considering that a stronger stimulus is required to stimulate people's responses, a 5-min equivalent SPL was adjusted to 70 $\mathrm{dB}(\mathrm{A})$ for each audio frequency to rule out loudness differences for the four 
soundscape types (Liu \& Kang, 2018; Jambrošić, Horvat, \& Domitrović, 2013). The stimuli were edited by the E-prime software and presented randomly. The spectra of the four soundscape types changing with time are shown in Figure 2. The birdsong was mainly concentrated in the high frequency region, while the sound of the ocean had an obvious rhythm. The street sound mainly contained medium and low frequency human and mechanical noises, while the traffic noise included low frequency noises and car whistle sounds. The audio recordings were played by Sennheiser RS170 headphones, and the videos were presented using a Samsung UA75H6400 screen.

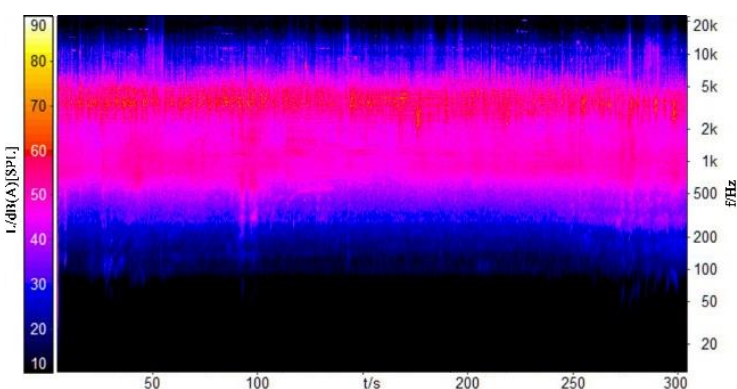

(a) Birdsong

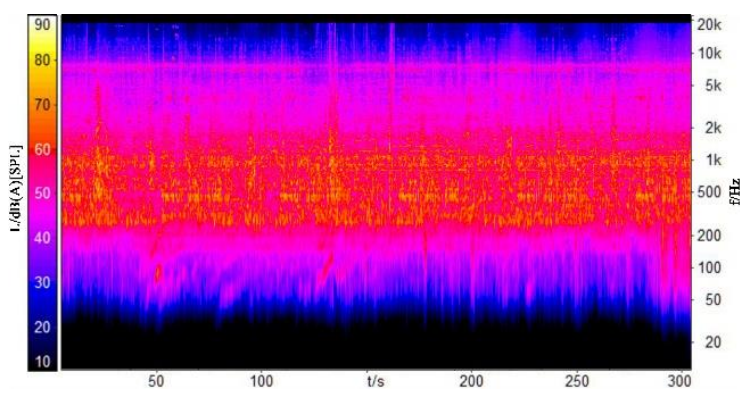

(c) Street

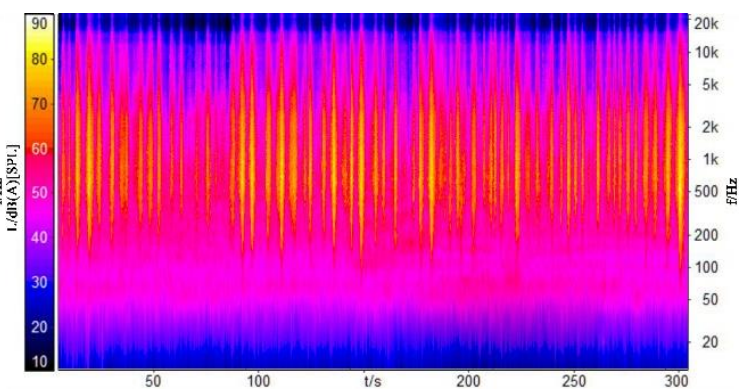

(b) Ocean

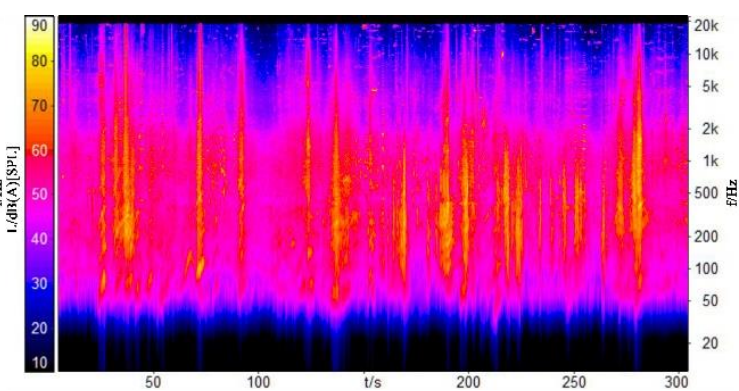

(d) Traffic

Figure 2. Typical spectra (FFT vs Time) of the four soundscape types.

\subsection{Physiological measurements}

Physiological signals were monitored by a BIOPAC MP160 system. The measured physiological indicators included ECGs (the positive and negative poles were alternated between the left and right wrists, while the grounding electrode was attached to the right foot); EEGs (the F7, F8, T3, T4, T5, T6, C3, C4, and $\mathrm{Cz}$ electrodes were attached at their proper positions, and the reference electrodes were placed on the subject's left and right earlobes) (Teplan, 2002; Sperry, 1974); electrooculograms (EOGs; the positive pole was attached above the left eye, and the negative pole - below the left eye); respiratory waves (the sensor was fixed to the chest through a respiratory band), skin conductance (measured on the medial 
surface of the non-dominant $2 \mathrm{nd} / 3 \mathrm{rd}$ finger), and body surface temperature (measured at the back of the hand). With the exception of a special respiratory band for detecting respiratory waves and temperature probe for measuring the body surface temperature, all other testing equipment was attached to the skin via $(\mathrm{Ag} / \mathrm{AgCl})$ standard electrode sheets. The stimuli were sent to a BIOPAC system through an STP100C module, and the detected physiological signals were analysed by the AcqKnowledge 5.0 software. The measured 10 physiological indicators included the HR (the reciprocal of the peak period of the R-wave), amplitude of the R-wave $(\Delta \mathrm{R})$, heart rate variability (HRV) calculated by the SDNN method (because the measurement of HRV may cause minor errors in different sitting position, the changing trend of the same subject in different soundscapes was studied by data normalisation in the following analysis), $\alpha$-EEG reactivity (determined via filtering at the main frequency of $8-13 \mathrm{~Hz}$ after removing the ocular EEG artefact), $\beta$-EEG reactivity (determined via filtering at the main frequency of $14-30 \mathrm{~Hz}$ after removing the ocular EEG artefact), eye blink frequency $(\mathrm{BF}$; calculated from the number of peaks of the EOG wave per unit time), respiratory frequency (RF; calculated from the peak-to-peak distance of the respiratory wave), respiratory depth ( $\mathrm{RD}$; calculated from the amplitude of the respiratory wave), skin conductance level (SCL), and skin temperature (ST).

\subsection{Subjective ratings}

The study used the perceived restorativeness soundscape scale (PRSS) as a subjective questionnaire to evaluate the restoration of soundscapes comprehensively and effectively (Hartig \& Staats, 2003; Hartig et al., 1996; Payne, 2013). The questionnaire included the following metrics: Fascination (the ability of a stimulus to have attention-holding properties), Being-Away-To (the pull factors that shift away from the present situation to a different environment), Being-Away-From (the push factors that shift away from the present situation to a different environment), Compatibility (the consistency between the environment and individual feelings), Coherency (the connectedness of the elements in the environment with their structure), and Scope (the scale of the environment), which contained a total of 19 items. Each question was answered on a five point scale in response to 'how much do you agree with the statement. . .?': not at all (1), a little (2), somewhat (3), a fair bit (4), completely (5). The questions were edited by the E-prime software and answered by the test subjects while looking at the computer screen and clicking on a selected answer at the end of the test sheet (Ba \& Kang, 2019a). 


\subsection{Experimental procedure}

The experiment was performed in a soundproof audiometric room, whose walls were covered with a special sound-absorbing material to reduce the reverberation effect and background noise. Apart from the required experimental equipment, no other distracting objects were present inside the room (Cadena, Soares, Pavón, \& Coelho, 2017; Lindquist, Lange, \& Kang, 2016). The participants were asked to sit comfortably at a distance of $1.5 \mathrm{~m}$ from the screen. The investigator explained the entire experimental procedure and asked the participants about their physical and mental states. After the subjects understood all the terms and agreed to them, the investigator connected the BIOPAC MP160 system and put on the headphones. After the connection process was complete and the physiological signal was calibrated, the E-prime software was started. First, the 5-min data set acquired in the resting state was used as the baseline for each physiological indicator. Subsequently, the investigator left the audiometric room and entered the observation room. The experiment was initiated automatically in $10 \mathrm{~s}$ after the participants pressed the start buttons. Four typical soundscapes with durations of 5 min were presented randomly, and the interval between two soundscapes was $90 \mathrm{~s}$. Alvarsson et al. (2010) suggested that the recovery half-life of SCL might be about $120 \mathrm{~s}$; however, in their study, the silent environment was used as the interval. Considering that extremely long intervals can make subjects feel bored or irritable, the interval time in the experiment was shortened to $90 \mathrm{~s}$. After all four soundscapes were presented, the physiological monitoring process was finished. The investigator re-entered the audiometric room, removed the headphones and electrodes, asked the subjects to fill out the questionnaire, and ended the experiment. After listening to all the sound stimuli, the subjects could make a more comprehensive and unified evaluation of the four soundscapes. The questionnaire was edited by E-prime and presented to the subjects on the TV screen. During the evaluation, the computer automatically played back the corresponding sound, and the selected answer was automatically stored by clicking the mouse. The process of physiological signal recording is illustrated in Fig. 3. 


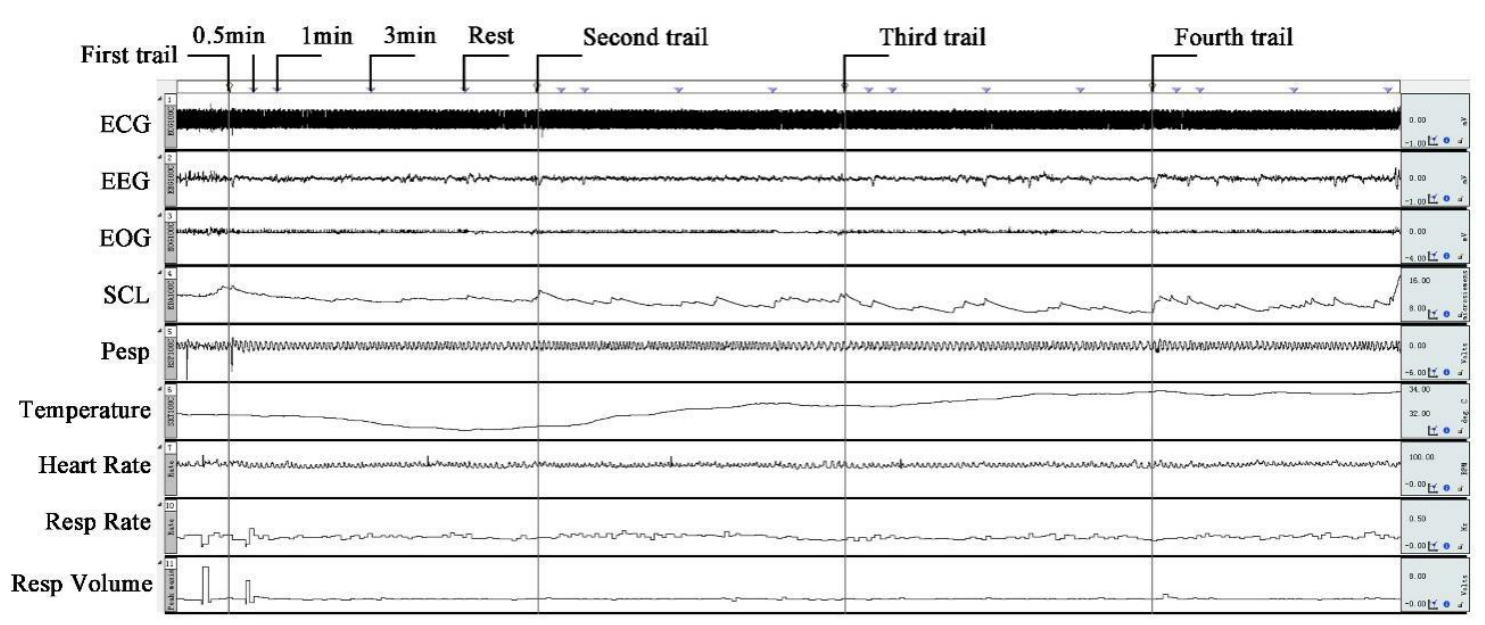

Figure 3. Recording of physiological signals.

\subsection{Data analysis}

Because of the significant differences between individuals, all physiological signals had to be normalised. The data obtained five minutes before the start of the experiment in the resting state were used as the baseline, and each physiological data set was converted into a relative deviation from the baseline value according to the following formula:

Relative change $(\%)=($ (raw value - baseline value $) /$ baseline value $) * 100$

By performing these calculations, all data points were normalised with respect to the baseline in the resting state. They no longer represented the actual physiological indicators; however, all individual differences between the subjects were removed, and the processed data could be compared with the results obtained in the absence of soundscape stimuli.

IBM SPSS 25.0 software was used to create a database containing the final results (Ba \& Kang, 2019b; Kang \& Zhang, 2010; Pallant, 2005). The data were analysed by the following methods. (1) The differences between the physiological indicators measured at different times and soundscape types were determined by the repeated measures analysis of variance. (2) The reliability and validity of the questionnaire were examined. Factor analysis was used to synthesise subjective evaluation factors. (3) The physiological indicators and subjective evaluation factors were subjected to canonical correlation analysis.

\section{Results and Discussion}

3.1. Changes in physiological indicators with time

The physiological indicators measured after $0.5,1,3$, and 5 min were 
considered time variables in SPSS, and four typical soundscape types were used as intersubjective factors for the repeated measures analysis of variance. The obtained results are listed in Table 1, where the multivariate variance statistical test is based on Pillai's trace. Using these data, marginal means were determined for the cross terms of the mode factors, and the corresponding broken line plots were drawn (see Fig. 4).

Table 1. Repeated measures tests of various physiological indicators.

\begin{tabular}{|c|c|c|c|c|c|c|}
\hline Indicator & M' Sig. & Effect & Value & $\mathrm{F}$ & df & Sig. \\
\hline \multirow{2}{*}{ HR } & \multirow{2}{*}{0.000} & Time & 0.110 & 13.283 & 3 & 0.000 \\
\hline & & Time * Sound Type & 0.166 & 4.745 & 12 & 0.000 \\
\hline \multirow{2}{*}{$\Delta \mathrm{R}$} & \multirow{2}{*}{0.000} & Time & 0.045 & 4.026 & 3 & 0.008 \\
\hline & & Time $*$ Sound Type & 0.085 & 2.533 & 9 & 0.007 \\
\hline \multirow{2}{*}{ HRV } & \multirow{2}{*}{0.000} & Time & 0.066 & 6.050 & 3 & 0.001 \\
\hline & & Time $*$ Sound Type & 0.123 & 3.715 & 9 & 0.000 \\
\hline \multirow{2}{*}{$\alpha-\mathrm{EEG}$} & \multirow{2}{*}{0.000} & Time & 0.004 & 0.378 & 3 & 0.769 \\
\hline & & Time $*$ Sound Type & 0.131 & 3.947 & 9 & 0.000 \\
\hline \multirow{2}{*}{$\beta$-EEG } & \multirow{2}{*}{0.000} & Time & 0.228 & 25.439 & 3 & 0.000 \\
\hline & & Time $*$ Sound Type & 0.108 & 3.224 & 9 & 0.001 \\
\hline \multirow{2}{*}{$\mathrm{BF}$} & \multirow{2}{*}{0.000} & Time & 0.067 & 6.221 & 3 & 0.000 \\
\hline & & Time * Sound Type & 0.035 & 1.031 & 9 & 0.413 \\
\hline \multirow{2}{*}{$\mathrm{RF}$} & \multirow{2}{*}{0.000} & Time & 0.077 & 7.197 & 3 & 0.000 \\
\hline & & Time * Sound Type & 0.102 & 3.035 & 9 & 0.001 \\
\hline \multirow{2}{*}{$\mathrm{RD}$} & \multirow{2}{*}{0.000} & Time & 0.079 & 7.327 & 3 & 0.000 \\
\hline & & Time $*$ Sound Type & 0.099 & 2.966 & 9 & 0.002 \\
\hline \multirow{2}{*}{ SCL } & \multirow{2}{*}{0.000} & Time & 0.322 & 40.862 & 3 & 0.000 \\
\hline & & Time $*$ Sound Type & 0.127 & 3.823 & 9 & 0.000 \\
\hline \multirow{2}{*}{ ST } & \multirow{2}{*}{0.000} & Time & 0.259 & 29.999 & 3 & 0.000 \\
\hline & & Time * Sound Type & 0.059 & 1.745 & 9 & 0.075 \\
\hline
\end{tabular}




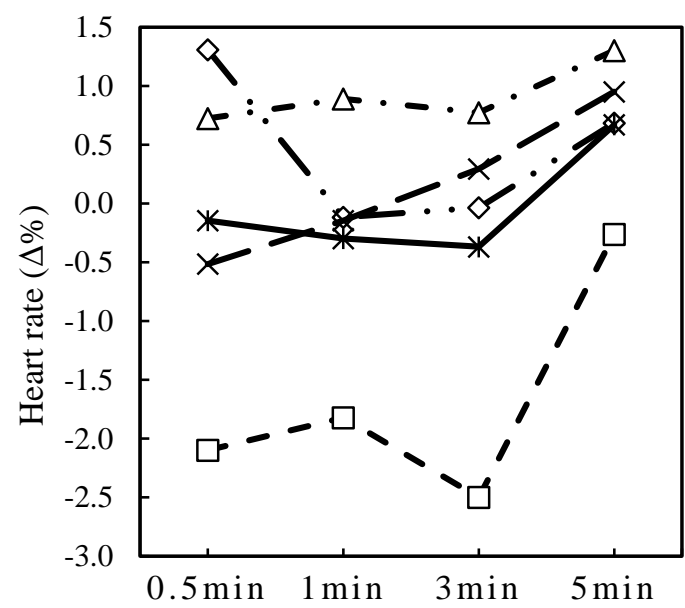

(a)

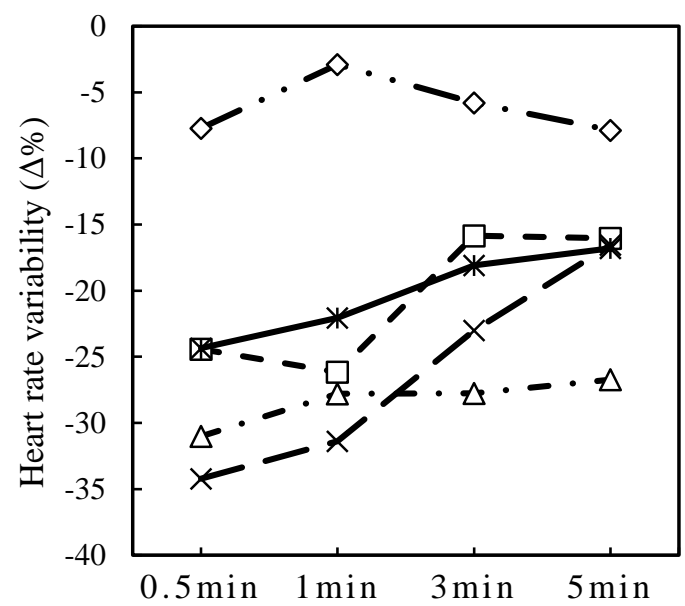

(c)

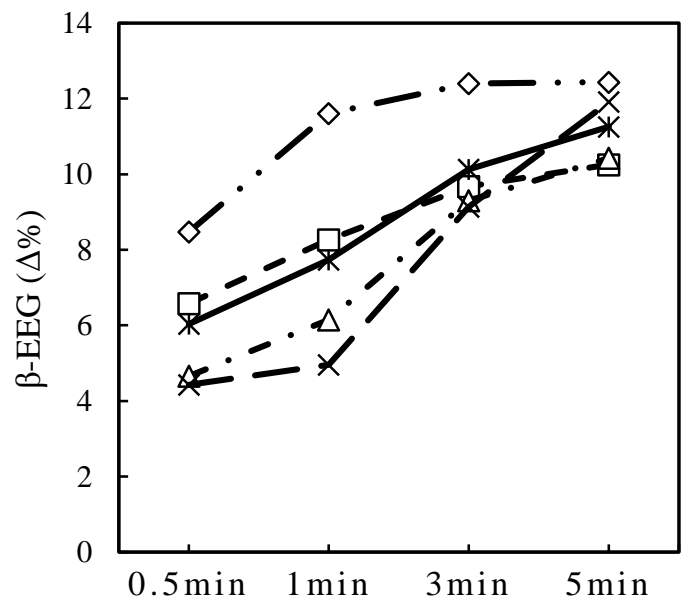

(e)

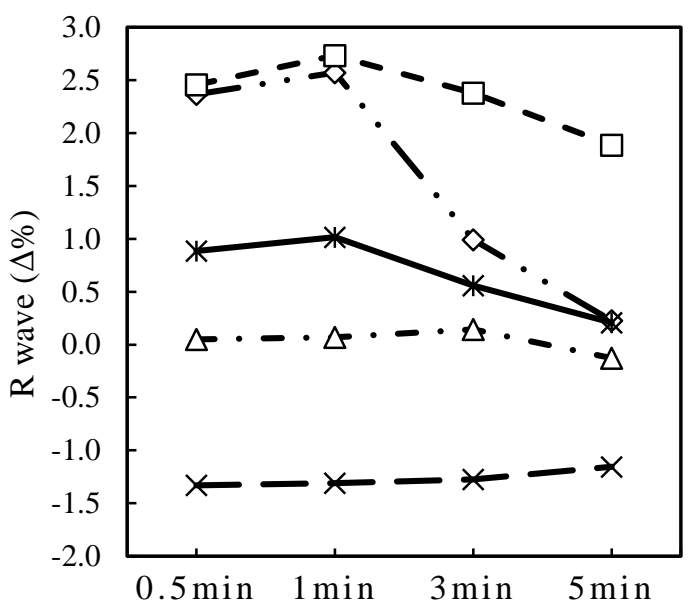

(b)

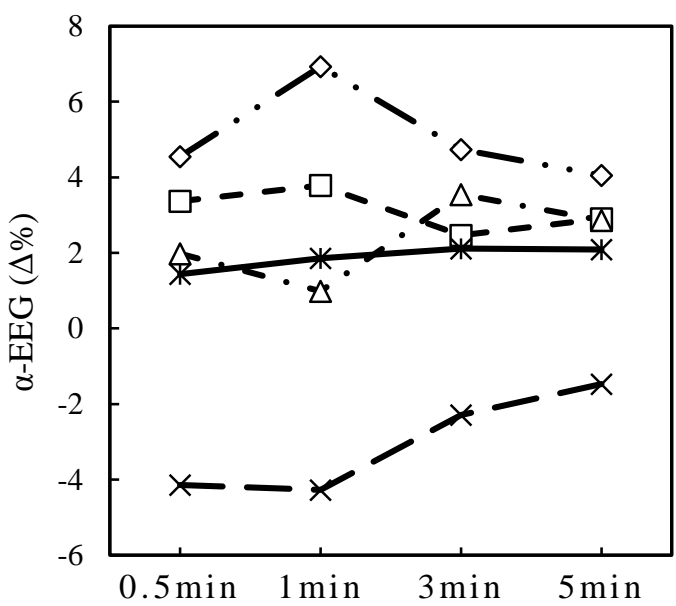

(d)

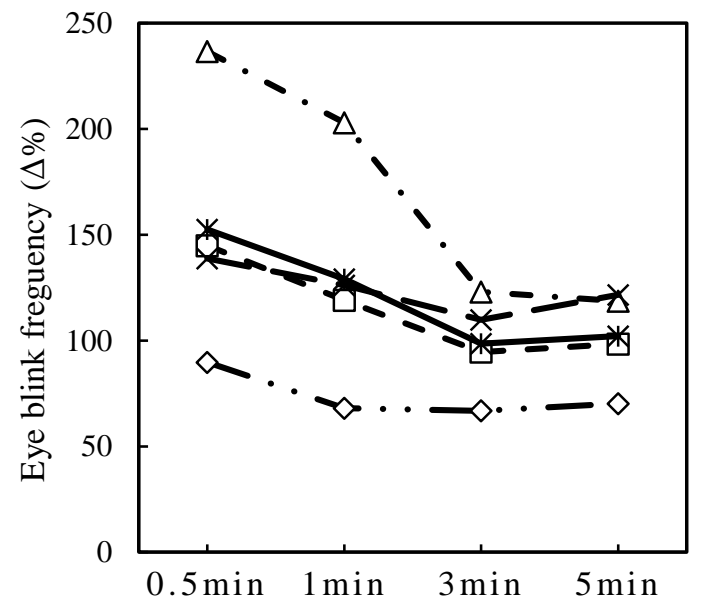

(f) 


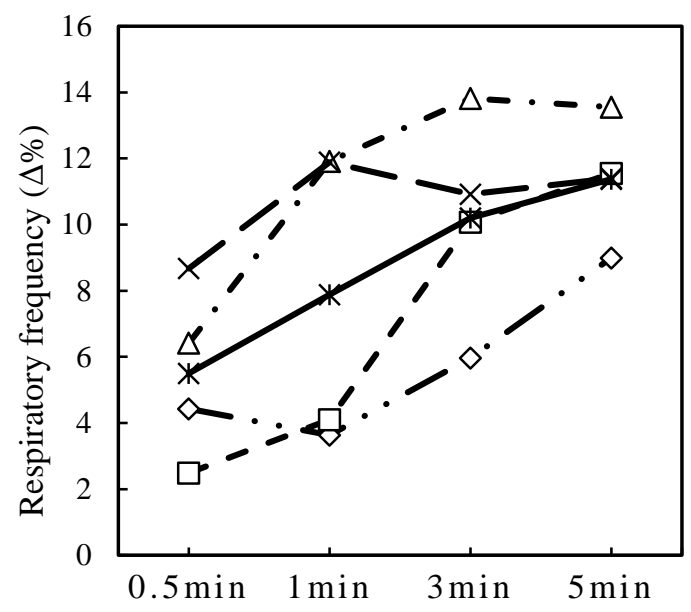

$(\mathrm{g})$

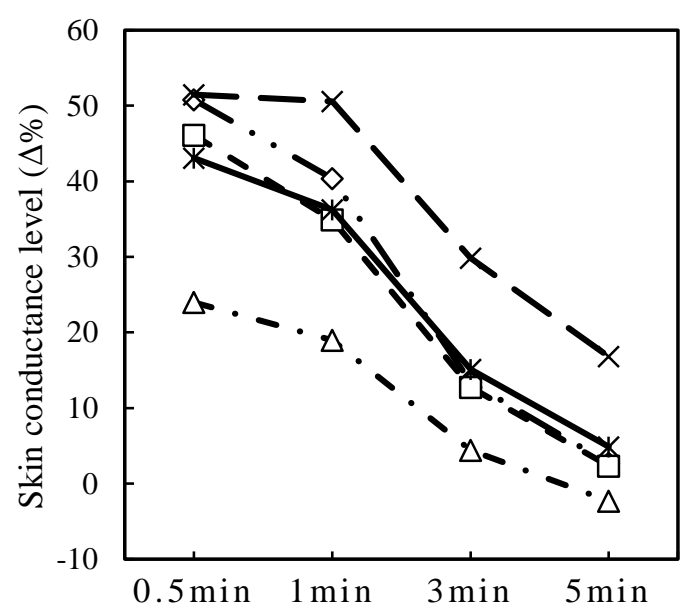

(i)

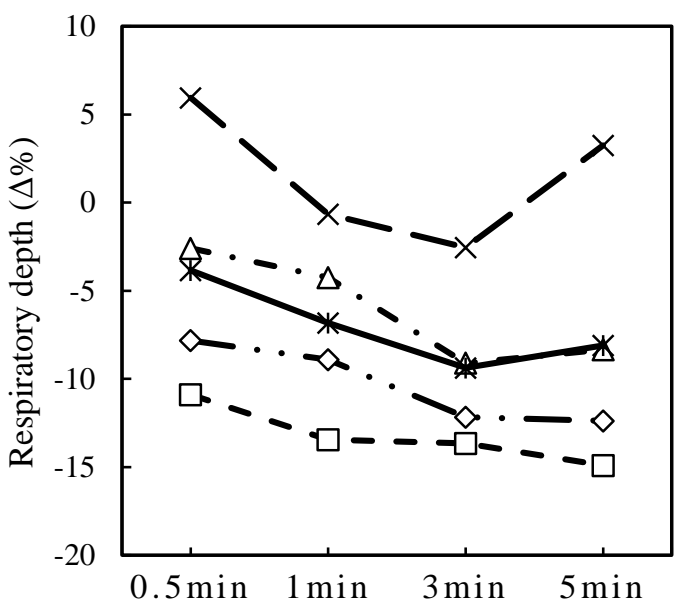

(h)

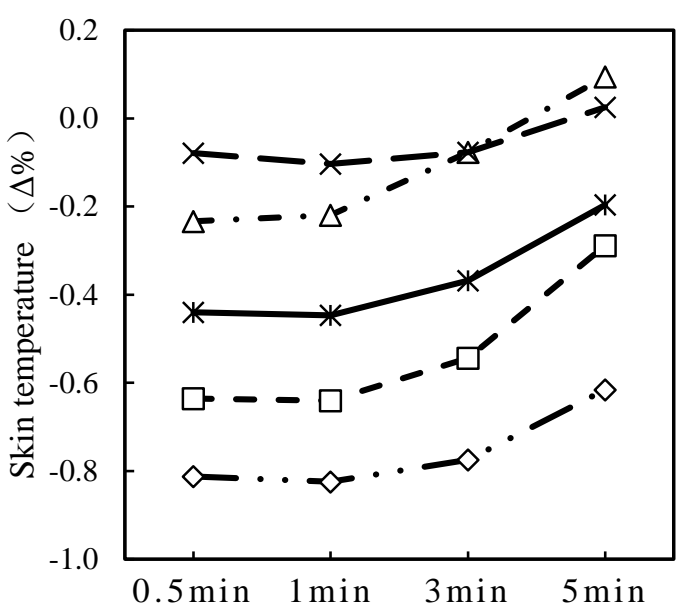

(j)

$\longrightarrow$ Ocean $-\square \cdot$ Birdsong $-\Delta-$ Street $\rightarrow-$ Traffic $\rightarrow$ Average

Figure 4. Changes in the physiological indicators with time and the soundscape type.

As shown in Table 1, the results of the Mauchley sphericity test were significant for all physiological indicators $(0.000<0.05)$, indicating that 1$)$ all the obtained data did not conform to the spherical hypothesis; 2) the results of all repeated measures were correlated; and 3 ) the results of the multiple tests were credible (see Figure 4 and Table 1).

(a) HR: In general, the HR changed slowly within the first three minutes and slightly decreased with respect to the baseline value. After three minutes, its magnitude increased more significantly. Nevertheless, the overall change in HR was not clear, and its average value after 5 min was only $0.669 \%$ higher than that in the 
resting state.

(b) $\Delta \mathrm{R}$ : Overall, the variation of $\Delta \mathrm{R}$ with time was the highest one at $1 \mathrm{~min}$, after which its magnitude decreased. The changes in traffic and street activity with time were not obvious, but the decreases in the values obtained for the ocean and birdsong soundscapes were distinct after one minute of experiment.

(c) HRV: Its value increased gradually with time from -24.345 to -16.796 , except for the ocean soundscape, which reached maximum at $1 \mathrm{~min}$ and then decreased gradually.

(d) $\alpha$-EEG: As shown in Table 1, the significance of $\alpha$-EEG is $0.769>0.05$, and the trend of the image change was moderate, indicating that the $\alpha$-EEG variation in the time dimension was not significant.

(e) $\beta$-EEG: The frequency of $\beta$-EEG exhibited the same upward trend for each soundscape with time, corresponding to an increase from 6.034 to 11.259.

(f) BF: Its magnitude reached 152.471 in the first $0.5 \mathrm{~min}$ and then decreased significantly to 102.163 , which was twice as high as the baseline value.

(g) RF: The same trend was observed for different soundscapes, corresponding to an increase from 5.499 to 11.376 . However, after $1 \mathrm{~min}$, the magnitudes obtained for the street and ocean soundscapes reached maxima.

(h) RD: Overall, the RD decreased from -3.846 to -8.096 , which indicated that the respiration became shallower with an increase in the test time.

(i) SCL: The changes in SCL with time exhibited the same trend for the four soundscapes, and its overall value decreased gradually from 43.078 to 4.871 . The obtained results showed that the SCL was very high at the beginning of the experiment. With increasing time, the SCL decreased significantly. Moreover, no differences were observed between the SCL and baseline value at the later stage of the experiment.

(j) ST: The overall trend of the change in ST was the same. With the increase in time, its value increased gradually from -0.440 at $0.5 \mathrm{~min}$ to -0.196 at $5 \mathrm{~min}$. Although the increasing trend was significant, the observed change in ST was very small.

How long can a human being exhibit a physiological effect under the action of a soundscape? How long does it take for a person to reach physiological habituation and recovery when exposed to sounds? The obtained physiological data show that not all indicators gradually approach the baseline value with an increase in time. In other words, certain physiological responses (such as $\beta$-EEG, RF, and RD) do not 
flatten out with time. According to Fig. 4, with increasing time, the RF increases, and the RD decreases, which indicates that people gradually become short of breath after being immersed into a soundscape (this trend was more pronounced after 5 $\min )$. The $\beta$-EEG value also increased with time. In contrast, the $\alpha$-EEG level was relatively stable and did not change with time. However, the individual broken lines obtained for each soundscape (even the $\alpha$-EEG one) showed that the majority of the physiological indicators exhibited a distinct inflection point at $1 \mathrm{~min}$. The relatively sensitive physiological indicators (such as HRV and SCL) changed immediately under the action of the soundscapes, whereas the variations of such indicators as respiration and $\Delta \mathrm{R}$ were not noticeable after half a minute. Thus, the obtained data revealed that all physiological indicators have responded to the corresponding stimuli within a minute and that the sensitive indicators were flattened over this period. Therefore, one minute is a reasonable timeframe for the observation of physiological indicators.

\subsection{Effects of the soundscape type on physiological indicators}

From the results of repeated measures variance analysis, the marginal means of all physiological indicators obtained under the actions of different soundscapes were calculated (see Table 2). At the same time, four soundscapes were pairwise compared by the S-N-K method, which classified the variables in the form of a subset (different symbols are used to represent soundscapes in the different subsets of Table 2). Using the data presented in Table 1 and Fig. 4, the effects of the soundscape type on each physiological indicator were determined.

Table 2. Marginal means of various physiological indicators determined for different soundscapes.

\begin{tabular}{ccccc}
\hline & Birdsong & Ocean & Traffic & Street \\
\hline $\mathrm{HR}$ & $-1.671 \star$ & $0.460 \Delta$ & $0.147 \Delta$ & $0.922 \Delta$ \\
$\Delta \mathrm{R}$ & $2.363 \Delta$ & $1.539 \star$ & $-1.267 \star$ & $0.033 \star$ \\
$\mathrm{HRV}$ & $-28.328 \star$ & $-6.075 \Delta$ & $-26.285 \star$ & $-28.328 \star$ \\
$\alpha-\mathrm{EEG}$ & $3.130 \Delta$ & $5.065 \Delta$ & $-3.042 \star$ & $2.342 \Delta$ \\
$\beta$-EEG & $8.694 \star$ & $11.231 \star$ & $7.608 \star$ & $7.634 \star$ \\
$\mathrm{BF}$ & $114.179 \star$ & $73.651 \star$ & $124.058 \star$ & $170.269 \star$ \\
$\mathrm{RF}$ & $7.056 \star$ & $5.755 \star$ & $10.719 \star$ & $11.427 \star$ \\
$\mathrm{RD}$ & $-13.227 \star$ & $-10.325 \star \Delta$ & $1.491 \Delta$ & $-6.073 \star \Delta$ \\
\hline
\end{tabular}




\begin{tabular}{ccccc}
\hline SCL & $24.027 \star$ & $26.812 \star$ & $37.169 \star$ & $11.267 \star$ \\
ST & $-0.527 \star$ & $-0.757 \star$ & $-0.059 \star$ & $-0.109 \star$ \\
\hline
\end{tabular}

Note: The listed mean values correspond to the marginal mean values that do not take into account the effect of the time factor. The differences between various groups were compared by the $\mathrm{S}-\mathrm{N}-\mathrm{K}$ method, and the four soundscapes were divided into one or two homogeneous subsets. The symbols $\star$ and $\Delta$ represent the homogeneous subsets 1 and 2 , respectively.

(a) HR: Overall, the lowest HR value was obtained in the birdsong soundscape. The ocean and traffic soundscapes produce slightly stronger effects, and their HR magnitudes did not significantly differ from the baseline. The highest HR value was achieved for the street soundscape within the first three minutes. The results showed that the HR of people exposed to the birdsong was significantly lower than that of the people exposed to the other three kinds of sound.

(b) $\Delta \mathrm{R}$ : The order of the $\Delta \mathrm{R}$ values (from the lowest to the highest ones) obtained under the actions of the four soundscapes was as follows: traffic, street, ocean, and birdsong. Statistically, the $\Delta \mathrm{R}$ of the birdsong was significantly different from the values obtained for the other three soundscapes. In addition, the $\Delta \mathrm{R}$ of the natural sounds (birdsong and ocean) was much higher than that of the noise (street and traffic).

(c) HRV: The HRV values of the street sound, traffic sound, and birdsong were very low, and their corresponding curves crossed, indicating the absence of significant differences between them. The HRV of the wave sound was relatively high and significantly different from the other three soundscape. In addition, the HRV values of all soundscapes were lower than the baseline value.

(d) $\alpha$-EEG: The $\alpha$-EEG of the traffic sound was the lowest one. In contrast, the $\alpha$-EEG of the ocean sound was the highest one and significantly different from the other three kinds of soundscape. Overall, the a-EEG of the natural sound was higher than that of the noise.

(e) $\beta$-EEG: The $\beta$-EEG decreased in the order of the ocean, birdsong, street, and traffic sounds. Although the results of the test showed that the effect of the soundscape type on $\beta$-EEG was substantial, no significant differences were observed between the four soundscapes. Similar to the trend obtained for a-EEG, the $\beta$-EEG of the natural sound was also higher than that of the noise.

(f) BF: Because the soundscape type had no effect on BF, a comparison of its mean values was meaningless. As a result, BF was no longer analysed in this study. 
(g) RF: Although the test results showed that the impact of the soundscape type on RF was significant, the four soundscapes exhibited no statistical differences.

(h) RD: The RD of the birdsong was the lowest one. The values obtained for the ocean and street sounds were ranked the second, and the RD of the traffic soundscape was the highest one. Combined with the RF data, the natural sound made people breathe more slowly, and the depth of breathing decreased. On the contrary, when exposed to the noise, people breathe more rapidly and violently.

(i) SCL: The smallest SCL was obtained for the street soundscape, and the largest one - for the traffic one. Although the soundscape types presented in Table 1 had a significant impact on SCL, the statistical analysis put the four soundscapes into the same group after comparison.

(j) ST: Overall, the soundscape type had little effect on ST, whose change measured after a minute was only $0.8 \%$ lower than the other values (including the magnitude obtained for the ocean sound with the lowest mean). These results indicate that the body surface temperature was stable and thus could not be considered a suitable indicator. Therefore, it is not discussed in the remaining parts of this paper.

Except for the two physiological indicators, which were not affected by the soundscape type, the other parameters produced significant differences. If the birdsong and ocean soundscapes are classified as natural sounds, and the street and traffic sounds as noise, a significant difference can be observed between them. Thus, the natural sounds can decrease the FR, RF, and RD magnitudes and increase the values of $\Delta \mathrm{R}, \mathrm{HRV}, \alpha$-EEG, and $\beta$-EEG. However, the boundary between the natural sounds and noise was not so distinct in the case of SCL. This phenomenon was consistent with the conclusion that unpleasant sounds could cause a significant decrease in HR and a small increase in RF (Hume \& Ahtamad, 2013). The simulation of traffic resulted in the highest SCL magnitude, but the SCL of the noisy street was lower than those of the birdsong and ocean sound, which was somewhat different from the results obtained by Alvarsson et al. (2010). This inconsistency can be explained by the fact that the SCL indicator was very sensitive, while the street noise was not louder than the ocean and forest soundscapes; however, the street sound was the most familiar one out of the four soundscape types. Perhaps, different SCL data can be obtained when the four soundscapes are reverted to different SPLs. 
3.3. Correlation between the physiological indicators and results of subjective evaluation

The reliability of the used questionnaire was characterised by Cronbach's alpha coefficient, while the Kaiser-Meyer-Olkin (KMO) test was used to evaluate its construct validity. The obtained results are listed in Table 3. The overall reliability of the questionnaire was high (as indicated by the Cronbach's alpha coefficient of 0.888 ), and the construct validity was also high corresponding to a KMO criterion of 0.921 . The Scope factor had only one item; therefore, it could not be used to determine the reliability and validity parameters of the questionnaire; nevertheless, their values obtained for the other dimensions were generally around 0.8 .

Table 3. Reliability and validity parameters of the used questionnaire.

\begin{tabular}{ccccc}
\hline Factor & $\begin{array}{c}\text { Cronbach's } \\
\text { alpha } \\
\text { coefficient }\end{array}$ & KMO criterion & $\begin{array}{c}\text { Bartlett's test of } \\
\text { sphericity }\end{array}$ & $\begin{array}{c}\text { Number } \\
\text { of items }\end{array}$ \\
\hline Fascination & 0.889 & 0.818 & 0.000 & 5 \\
Being-Away-To & 0.805 & 0.733 & 0.000 & 3 \\
Being-Away-From & 0.885 & 0.696 & 0.000 & 3 \\
Compatibility & 0.860 & 0.750 & 0.000 & 4 \\
Coherency & 0.671 & 0.641 & 0.000 & 3 \\
Scope & - & - & - & 1 \\
Total & 0.888 & 0.921 & 0.000 & 19 \\
\hline
\end{tabular}

The six PRSS dimensions were subjected to factor analysis, and the corresponding common factors were extracted. In this experiment, factor analysis was performed separately for different factors, so that a correlation still existed between the factors for subsequent analysis. The obtained component data are listed in Table 4. Except for Scope, the total variance of the explanation of the common factors (such as Fascination) was over $60 \%$, and the extracted factors were also greater than 0.5; hence, the latter strongly contributed to the common factors. Each common factor was saved as a new variable in the form of standardisation, and Scope was also calculated as a new variable through a $\mathrm{Z}$-score standardisation procedure. As a result, standardised subjective evaluation data were obtained for the six dimensions, which was convenient for further statistical analysis and 
calculations.

Table 4. Factor analysis of the subjective questionnaire.

\begin{tabular}{|c|c|c|c|c|}
\hline Factor & $\begin{array}{l}\text { Cumulative } \\
\text { variance }\end{array}$ & Item & Extraction & Component \\
\hline \multirow{5}{*}{ Fascination } & \multirow{5}{*}{$69.528 \%$} & Appealing & 0.864 & 0.929 \\
\hline & & Attention & 0.523 & 0.723 \\
\hline & & Linger & 0.785 & 0.886 \\
\hline & & Wonder & 0.702 & 0.838 \\
\hline & & Engrossed & 0.603 & 0.776 \\
\hline \multirow{3}{*}{ Being-Away-To } & \multirow{3}{*}{$80.257 \%$} & Doing_different & 0.758 & 0.871 \\
\hline & & Different_sonic & 0.824 & 0.908 \\
\hline & & Usually_hear & 0.825 & -0.908 \\
\hline \multirow{3}{*}{$\begin{array}{c}\text { Being-Away-Fr } \\
\text { om }\end{array}$} & \multirow{3}{*}{$81.346 \%$} & Refuge & 0.856 & 0.925 \\
\hline & & Free & 0.705 & 0.840 \\
\hline & & Break & 0.879 & 0.938 \\
\hline \multirow{4}{*}{ Compatibility } & \multirow{4}{*}{$71.566 \%$} & Activities & 0.774 & 0.880 \\
\hline & & Fits & 0.838 & 0.916 \\
\hline & & Used_to & 0.632 & 0.795 \\
\hline & & Hinders & 0.619 & -0.786 \\
\hline \multirow{3}{*}{ Coherency } & \multirow{3}{*}{$60.597 \%$} & Belongs & 0.650 & 0.806 \\
\hline & & Coherent & 0.499 & 0.706 \\
\hline & & Together & 0.669 & 0.818 \\
\hline Scope & $100 \%$ & Limitless & 1.000 & 1.000 \\
\hline
\end{tabular}

The HR, $\Delta \mathrm{R}, \mathrm{HRV}, \alpha$-EEG, $\beta$-EEG, RF, RD, and SCL values determined for the four periods were combined into group 1. Fascination, Being-Away-To, Being-Away-From, Compatibility, Coherency, and Scope were combined into group 2. Canonical correlation analysis was performed on the two groups, and the obtained results are presented in Fig. 5, which shows the most significant pairs of the relationships existing between the two groups over the four periods. Among them, the first typical relation pair of each period was the first correlation structure extracted by the model. The second typical relation pair was extracted afterwards; 
hence, its correlation coefficient was smaller than that of the first pair. This study did not analyse the canonical correlation structure after the second pair, because in addition to the first two pairs of structures, the correlations between the subsequent canonical pairs were very weak (the corresponding proportions of variance are listed in Table 5). In this study, people's subjective evaluation of soundscapes was conducted through long time experience, while the measured physiological indicators were constantly changing. By performing canonical correlation analysis, the relationship between the physiological response time and overall feelings in various soundscapes can be determined.
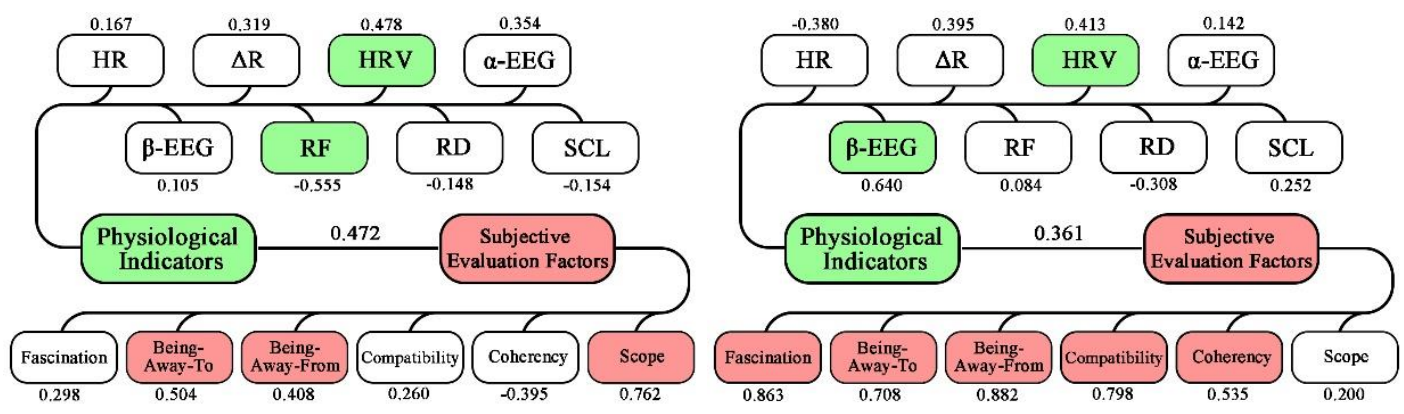

(a) First pair of the canonical correlation structures after $0.5 \mathrm{~min}$.

(b) Second pair of the canonical correlation structures after $0.5 \mathrm{~min}$.
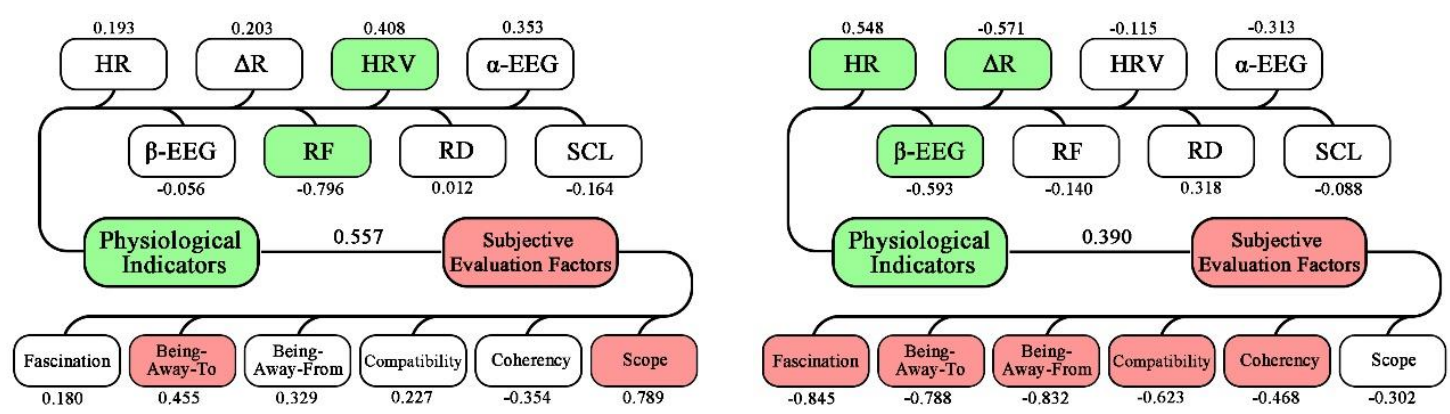

(c) First pair of the canonical correlation structures after $1 \mathrm{~min}$.

(d) Second pair of the canonical correlation structures after $1 \mathrm{~min}$.
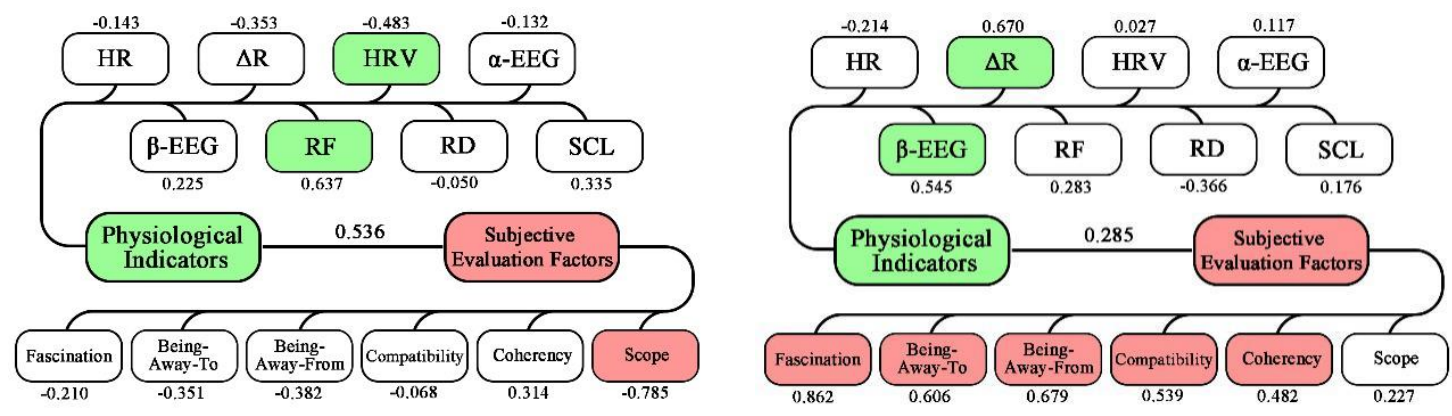

(e) First pair of the canonical correlation structures after 3 min.

(f) Second pair of the canonical correlation structures after 3 min. 

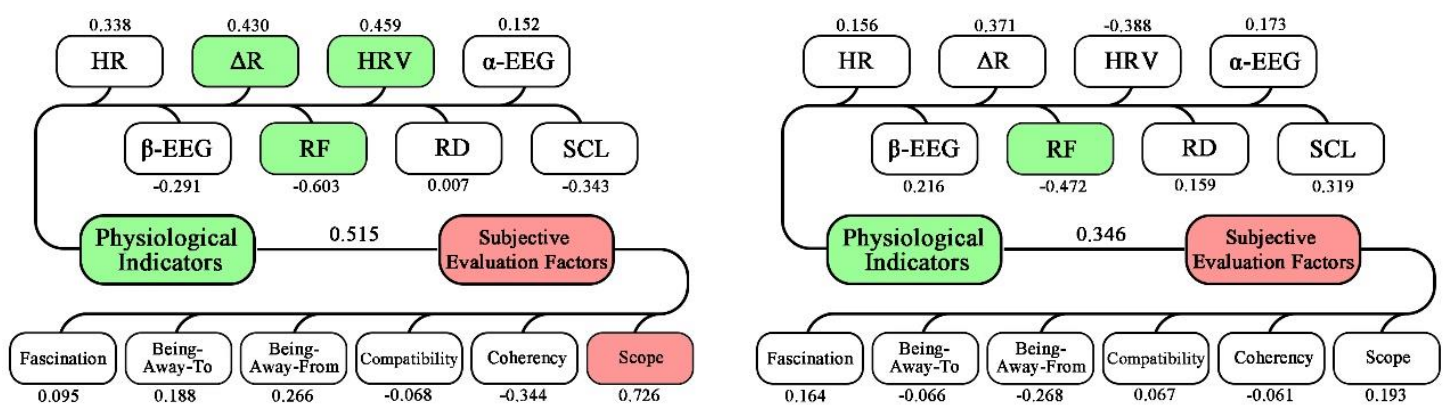

(g) First pair of the canonical correlation structures after $5 \mathrm{~min}$.

(h) Second pair of the canonical correlation structures after 5 min.

Figure 5. Structural diagrams describing the results of canonical correlation analysis.

As shown in Fig. 5a, the correlation coefficient between the physiological and subjective factors obtained for the first pair of typical structures within 0.5 min was 0.472. The physiological indicators producing the strongest effects were HRV and RF. The subjective group mainly included Being-Away-To, Being-Away-From, and Scope, which suggested that the lower was the rating of the subjective evaluation factors (such as that of Being-Away-To), the greater was the probability that the HRV would decrease and RF would increase. As can be seen from Fig. 5b, in the second pair of canonical correlation structures, the physiological indicators were mainly composed of HRV and $\beta$-EEG, and the subjective factors mainly included Fascination, Being-Away-To, Being-Away-From, Compatibility, and Coherency, suggesting that the stronger were these subjective evaluation factors, the higher were the HRV and $\beta$-EEG values. In the two canonical correlation pairs, $H R, \Delta R$, $\alpha$-EEG, RD, and SCL were not strongly related, indicating that the correlation between these physiological indicators and the subjective evaluation factors was not obvious (these parameters were also not included into the first two canonical correlation pairs). However, for the third canonical correlation pair, the degree of explanation of the structure in the overall model was negligible. In the first canonical correlation pair listed in Table 5, the degree of explanation of the change in the physiological indicators by themselves was $10.6 \%$, and the magnitude obtained for the subjective questionnaire was $2.4 \%$. The subjective questionnaire was able to explain $21.9 \%$ of its own variation and $4.9 \%$ of the variations of the physiological indicators. The parameters of the second canonical correlation pair were significantly lower than those of the first pair.

As illustrated in Fig. 5c, the trend obtained for the physiological indicators and subjective evaluation factors within $1 \mathrm{~min}$ was similar to that observed after $0.5 \mathrm{~min}$. 
The canonical correlation coefficient of the first pair increased to 0.557. However, in the first pair of the canonical correlation structure, only Being-Away-To and Scope were the main factors. Similarly, the second pair of the canonical correlation structures depicted in Fig. $5 \mathrm{~d}$ was similar to that observed within $0.5 \mathrm{~min}$, but the major physiological factors were HR, $\Delta \mathrm{R}$, and $\beta$-EEG. Therefore, the lower was the subjective evaluation rating, the higher was the HR, and the lower were the $\Delta R$ and $\beta$-EEG values measured within $1 \mathrm{~min}$. The $\alpha$-EEG, RD, and SCL indicators were not apparently reflected in the two structures. Table 5 shows that within the first minute, the degrees of explanation of the changes in the physiological indicators caused by the subjective questionnaire increased to 5.9 and $6.9 \%$. Although this improvement was relatively modest, the 1-min data were more convincing.

As shown in Figs. 5e and $\mathrm{f}$, the canonical correlation coefficients of the first and second pairs obtained after 3 min were 0.536 and 0.285 , respectively. Compared with the $0.5-\mathrm{min}$ and 1-min data, the canonical correlation structure of the first pair changed. Among the physiological indicators, the HRV and RF provided the strongest contributions, the subjective evaluation factors were limited to Scope, and the effect of Being-away-to decreased significantly. These results revealed that the smaller was the Scope value, the smaller was the HRV and the higher was the RF measured within the first $3 \mathrm{~min}$. In the second pair of structures, $\Delta \mathrm{R}$ and $\beta$-EEG were the main factors among the physiological indicators, whereas HR, $\alpha$-EEG, RD, and SCL were not reflected in the two pairs. The results listed in Table 5 show that the explanation degrees of the data obtained after 3 min noticeably decreased, and the explanation degrees of the changes in the physiological indicators caused by the subjective factors were only $4.9 \%$ and $2.9 \%$.

As shown in Fig. 5g and Fig. 5h, the coefficients obtained for the first and the second pairs of the canonical correlation structures within 5 min were 0.515 and 0.346, respectively. In the first pair, the main components of the physiological indicators were $\triangle R, H R V$ and $R F$, while among the subjective evaluation factors, only Scope demonstrated strong correlation. In the second pair, the RF was the main component among the physiological indicators, and no strong correlations between the subjective evaluation factors were observed. These results show that the correlation between the physiological indicators and subjective evaluation factors decreased significantly after $5 \mathrm{~min}$. Only $0.34 \%$ and $0.3 \%$ of the observed changes in the physiological indicators can be explained by the subjective evaluation factors.

In general, the correlation between the subjective evaluation and physiological data obtained within the first minute was stronger than that for the data obtained 
after $3 \mathrm{~min}$. In other words, people's subjective evaluation of restoration is strongly related to the physiological data obtained within one minute of the soundscape immersion. The results of canonical correlation analysis conducted for the physiological indicators and subjective evaluation factors confirmed the conclusions presented in section 3.1. In addition, the $\alpha$-EEG, RD, and SCL parameters were not correlated with the subjective evaluation data, indicating that the relationship between these three indicators and restorative evaluation factors might be very weak.

\section{Conclusions}

In this study, it was found that the physiological response of human beings was strongly affected by the measurement time and soundscape type as well as by the relationship between the physiological signal and subjective restorative scale. The differences between the physiological indicators and correlation between the physiological indicators and subjective evaluation factors were determined by performing variance and canonical correlation analyses. From the obtained results, the following conclusions can be drawn:

(1) All physiological indicators significantly changed with time except for $\alpha$-EEG. The strongest effect was observed after 1 min of measurements.

(2) The BF and ST indicators were not affected by the soundscape type. The difference between the natural sounds and noise was clear, and the former were able to decrease the HR, RF, and RD and increase the $\Delta \mathrm{R}, \mathrm{HRV}, \alpha-\mathrm{EEG}$, and $\beta$-EEG values.

(3) A strong correlation exists between the physiological indicators and subjective evaluation factors, and its maximum strength was observed after 1 min of measurements. However, the subjective evaluation factors interpret the physiological changes very poorly.

In this work, only the physiological reactions were studied and analysed. Whether the change of a physiological indicator is purely physiological or involves emotions as well will be the subject of future research. In addition, only four typical soundscapes out of many varieties were experimentally analysed. Despite the existence of a strong correlation between the physiological indicators and subjective evaluation factors, their ability to interpret experimental data is very poor, suggesting that it is difficult to use the existing restorative scale to estimate the real physiological state (this phenomenon might be explained by the use of only four typical soundscapes in this work). Can more regular physiological indicators be 
observed when a broader variety of soundscapes are considered? Is there a subjective scale that correlates well with physiological indicators? How can this scale be properly used to reflect the current physiological state with high accuracy? The solution of these problems can be obtained by considering a wider range of soundscape categories. At the same time, the results of 1-min experiments are also worthy of the in-depth discussion and detailed evaluation. Why do people react most strongly to the sound within $1 \mathrm{~min}$ ? A likely answer is that the soundscape perception is adjusted by the body after this period, and this conclusion may explain various phenomena such as inhabitation and recovery in soundscapes in future studies. More consideration should be given to the effects of the spectral characteristics, loudness, and duration of sound on the physiology as well as the impacts of changes in these physiological indicators on the human emotions or behaviour.

\section{References}

Alvarsson, J. J., Wiens, S., \& Nilsson, M. E. (2010). Stress recovery during exposure to nature sound and environmental noise. International Journal of Environmental Research and Public Health, 7, 1036-1046. https://doi.org/10.3390/ijerph7031036.

Ando, Y., \& Chen, C. (1996). On the analysis of autocorrelation function of $\alpha$-waves on the left and right cerebral hemispheres in relation to the delay Time of single sound reflection. Journal of Architecture and Planning (Transactions of AIJ), 61(488), 67-73. https://doi.org/10.3130/aija.61.67_4.

Annerstedt, M., Jönsson, P., Wallergård, M., Johansson, G., Karlson, B., Grahn, P., Hansen, A. M., \& Währborg, P. (2013). Inducing physiological stress recovery with sounds of nature in a virtual reality forest - Results from a pilot study. Physiology \& Behavior, 118, 240-250. https://doi.org/10.1016/j.physbeh.2013.05.023.

Axelsson, Ö., Nilsson, M.E., \& Berglund, B. (2010). A principal components model of soundscape perception. Journal of the Acoustical Society of America, 128, 2836-2846. https://doi.org/10.1121/1.3493436.

Ba, M., \& Kang, J. (2019a). A laboratory study of the sound-odour interaction in urban environments. Building and Environment, 147, 314-326. https://doi.org/10.1016/j.buildenv.2018.10.019.

Ba, M., \& Kang, J. (2019b). Effect of a fragrant tree on the perception of traffic noise. Building and Environment, 156, 147-155. 
https://doi.org/10.1016/j.buildenv.2019.04.022.

Blood, A. J., \& Zatorre, R. J. (2001). Intensely pleasurable responses to music correlate with activity in brain regions implicated in reward and emotion. Proceedings of the National Academy of Sciences of the United States of America, 98, 11818-11823. https://doi.org/10.1073/pnas.191355898.

Bradley, M. M., \& Lang, P. J. (2000). Affective reactions to acoustic stimuli. Psychophysiology, 37, 204-215. doi - 10.1111/1469-8986.3720204.

Cadena, L. F. H., Soares, A. C. L., Pavón, I., \& Coelho, L. B. (2017). Assessing soundscape: Comparison between in situ and laboratory methodologies. Noise Mapping, 4, 57-66. https://doi.org/10.1515/noise-2017-0004.

Chuen, L., Sears, D., \& McAdams, S. (2016). Psychophysiological responses to auditory change. Psychophysiology, 53, 891-904. doi - 10.1111/psyp. 12633.

Hartig, T., Evans, G. W., Jamner, L. D., Davis, D. S., \& Gärling, T. (2003). Tracking restoration in natural and urban field settings. Journal of Environmental Psychology, 23(2), 109-123. https://doi.org/10.1016/S0272-4944(02)00109-3.

Hartig, T., Korpela, K., Evans, G. W., \& Gärling, T. (1996). Validation of a measure of perceived environmental restorativeness. Göteborg, Sweden: Department of Psychology, Göteborg University.

Hartig, T., \& Staats, H. (2003). Guest editors' introduction. Journal of Environmental Psychology, 23(2), 103-107. http://dx.doi.org/10.1016/S0272-4944(02)00108-1.

Herzog, T. R., Colleen, Maguire, P., \& Nebel, M. B. (2003). Assessing the restorative components of environments. Journal of Environmental Psychology, 23(2), 159-170. https://doi.org/10.1016/S0272-4944(02)00113-5.

Hume, K., \& Ahtamad, M. (2013). Physiological responses to and subjective estimates of soundscape elements. Applied Acoustics, 74, 275-281. https://doi.org/10.1016/j.apacoust.2011.10.009.

Irwin, A., Hall, D. A., Peters, A., \& Plack, C. J. (2011). Listening to urban soundscapes: Physiological validity of perceptual dimensions. Psychophysiology, 48, 258-268. doi - 10.1111/j.1469-8986.2010.01051.x.

Jambrošić, K., Horvat, M. \& Domitrović, H. (2013). Assessment of urban soundscapes with the focus on an architectural installation with musical features. The Journal of the Acoustical Society of America, 134(1), 869-879. https://doi.org/10.1121/1.4807805.

Kang, J., Aletta, F., Gjestland, T. T., Brown, L. A., Botteldooren, D., 
Schulte-Fortkamp, B., Lercher, P., Van Kamp, I., Genuit, K., Fiebig, A., \& Coelho, J. L. B. (2016). Ten questions on the soundscapes of the built environment. Building and Environment, 108, 284-294. https://doi.org/10.1016/j.buildenv.2016.08.011.

Kang, J., \& Zhang, M. (2010). Semantic differential analysis of the soundscape in urban open public spaces. Building and Environment, 45, 150-157.

Kaplan, R., \& Kaplan, S. (1989). The experience of nature: A psychological perspective. Cambridge: Cambridge University Press.

Laumann, K., Gärling, T., \& Stormark, K. M. (2001). Rating scale measures of restorative components of environments. Journal of Environmental Psychology, 21(1), 31-44. https://doi.org/10.1006/jevp.2000.0179.

Lindquist, M., Lange, E., \& Kang, J. (2016). From 3D landscape visualization to environmental simulation: The contribution of sound to the perception of virtual environments. Landscape and Urban Planning, 148, 216-231. https://doi.org/10.1016/j.landurbplan.2015.12.017.

Liu, F., \& Kang, J. (2018). Relationship between street scale and subjective assessment of audio-visual environment comfort based on 3D virtual reality and dual-channel acoustic tests. Building and Environment, 129, 35-45. https://doi.org/10.1016/j.buildenv.2017.11.040.

Liu, J., Kang, J., Behm, H., \& Luo, T. (2014). Effects of landscape on soundscape perception: Soundwalks in city parks. Landscape and Urban Planning, 123, 30-40. https://doi.org/10.1016/j.landurbplan.2013.12.003.

Liu, J., Kang, J., Luo, T., \& Behm, H. (2013). Landscape effects on soundscape experience in city parks. Science of the Total Environment, 454-455, 474-481. https://doi.org/10.1016/j.scitotenv.2013.03.038.

Medvedev, O., Shepherd, D., \& Hautus, M. J. (2015). The restorative potential of soundscapes: A physiological investigation. Applied Acoustics, 96, 20-26. https://doi.org/10.1016/j.apacoust.2015.03.004.

Pallant, J. (2005). SPSS survival manual: A step by step guide to data analysis. NSW Australia: Allen \& Unwin Pty.

Payne, S. R. (2013). The production of a perceived restorativeness soundscape scale. Applied Acoustics, 74(2), 255-263. https://doi.org/10.1016/j.apacoust.2011.11.005.

Ratcliffe, E., Gatersleben, B., \& Sowden, P. T. (2013). Bird sounds and their contributions to perceived attention restoration and stress recovery. Journal of 
Environmental Psychology, 36, 221-228. https://doi.org/10.1016/j.jenvp.2013.08.004.

Sammler, D., Grigutsch, M., Fritz, T. \& Koelsch, S. (2007). Music and emotion: Electrophysiological correlates of the processing of pleasant and unpleasant music. Psychophysiology, 44, 293-304. doi 10.1111/j.1469-8986.2007.00497.x.

Sato, S., Nishio, K., \& Ando, Y. (2003). Propagation of alpha waves corresponding to subjective preference from the right hemisphere to the left with changes in the IACC of a sound field. Journal of Temporal Design in Architecture and the Environment, 3(1), 60-69.

Schmidt, L. A., \& Trainor, L. J. (2001). Frontal brain electrical activity (EEG) distinguishes valence and intensity of musical emotions. Cognition \& Emotion, 15, 487-500. https://doi.org/10.1080/02699930126048.

Shepherd, D., Hautus, M. J., Lee, S. Y., \& Mulgrew, J. (2016). Electrophysiological approaches to noise sensitivity. Journal of Clinical and Experimental Neuropsychology, 38 , 900-912. https://doi.org/10.1080/13803395.2016.1176995.

Shepherd, D., Welch, D., Dirks, K., \& McBride, D. (2013). Do quiet areas afford greater health-related quality of life than noisy areas? International Journal of Environmental Research and Public Health, 10. 1284-1303. https://doi.org/10.3390/ijerph10041284.

Sperry, R. W. (1974). Lateral specialization in the surgically separated hemispheres. In F. O. Schmitt, \& F. G. Worden (Eds.). The Neurosciences: Third study program (pp. 5-19). Cambridge: MIT Press.

Teplan, M. (2002). Fundamentals of EEG measurement. Measurement Science Review, 2(2), 1-11.

Ulrich, R. S., Simons, R. F., Losito, B. D., Fiorito, E., Miles, M. A., \& Zelson, M. (1991). Stress recovery during exposure to natural and urban environments. Journal of Environmental Psychology, 11, 201-230. https://doi.org/10.1016/S0272-4944(05)80184-7.

Van Kamp, I., Klaeboe, R., Kruize, H., Brown, A. L., \& Lercher, P. (2016). Soundscapes, human restoration and quality of life. In INTER-NOISE and NOISE-CON Congress and Conference Proceedings, 253(7), 1205-1215.

Von Lindern, E., Hartig, T., \& Lercher, P. (2016). Traffic-related exposures, constrained restoration, and health in the residential context. Health \& Place, 
39, 92-100. https://doi.org/10.1016/j.healthplace.2015.12.003. 